\title{
Release of free amino acids upon oxidation of peptides and proteins by hydroxyl radicals
}

\author{
Fobang Liu ${ }^{1}$ - Senchao Lai ${ }^{2}$ - Haijie Tong ${ }^{1}$ - Pascale S. J. Lakey ${ }^{1}$ Manabu Shiraiwa ${ }^{1,3}$. \\ Michael G. Weller ${ }^{4}$ - Ulrich Pöschl ${ }^{1}$ • Christopher J. Kampf ${ }^{1,5,6}$
}

Received: 28 October 2016 / Revised: 20 December 2016 / Accepted: 3 January 2017 / Published online: 20 January 2017

(C) The Author(s) 2017. This article is published with open access at Springerlink.com

\begin{abstract}
Hydroxyl radical-induced oxidation of proteins and peptides can lead to the cleavage of the peptide, leading to a release of fragments. Here, we used high-performance liquid chromatography tandem mass spectrometry (HPLC-MS/MS) and pre-column online ortho-phthalaldehyde (OPA) derivatization-based amino acid analysis by HPLC with diode array detection and fluorescence detection to identify and quantify free amino acids released upon oxidation of proteins and peptides by hydroxyl radicals. Bovine serum albumin (BSA), ovalbumin (OVA) as model proteins, and synthetic tripeptides (comprised of varying compositions of the amino acids Gly, Ala, Ser, and Met) were used for reactions with hydroxyl radicals, which were generated by the Fenton
\end{abstract}

Electronic supplementary material The online version of this article (doi:10.1007/s00216-017-0188-y) contains supplementary material, which is available to authorized users.

Christopher J. Kampf

c.kampf@mpic.de

1 Multiphase Chemistry Department, Max Planck Institute for Chemistry, Hahn-Meitner-Weg 1, 55128 Mainz, Germany

2 School of Environment and Energy, South China University of Technology, Higher Education Mega Center, Guangzhou 510006, China

3 Department of Chemistry, University of California, Irvine, 1102 Natural Sciences II, Irvine, CA 92697-2025, USA

4 Division 1.5 Protein Analysis, Federal Institute for Materials Research and Testing (BAM), Richard-Willstätter-Str. 11, 12489 Berlin, Germany

5 Institute for Inorganic and Analytical Chemistry, Johannes Gutenberg University Mainz, Duesbergweg 10-14, 55128 Mainz, Germany

6 Institute for Organic Chemistry, Johannes Gutenberg University Mainz, Duesbergweg 10-14, 55128 Mainz, Germany reaction of iron ions and hydrogen peroxide. The molar yields of free glycine, aspartic acid, asparagine, and alanine per peptide or protein varied between 4 and 55\%. For protein oxidation reactions, the molar yields of Gly $(\sim 32-55 \%$ for BSA, $\sim 10-21 \%$ for OVA) were substantially higher than those for the other identified amino acids $(\sim 5-12 \%$ for BSA, $\sim 4-6 \%$ for OVA). Upon oxidation of tripeptides with Gly in C-terminal, mid-chain, or N-terminal positions, Gly was preferentially released when it was located at the C-terminal site. Overall, we observe evidence for a site-selective formation of free amino acids in the $\mathrm{OH}$ radical-induced oxidation of peptides and proteins, which may be due to a reaction pathway involving nitrogen-centered radicals.

Keywords Peptides $\cdot$ Proteins $\cdot$ Oxidation $\cdot$ Hydroxyl radicals $\cdot$ HPLC-MS $\cdot$ Amino acid analysis

\section{Introduction}

Reactive oxygen species (ROS) have been associated with various diseases (e.g., diabetes and cancer), as they can cause oxidative stress, biological aging, and cell death [1-7]. The hydroxyl radical $(\mathrm{OH})$, the most reactive form of ROS, can oxidize most organic compounds such as proteins and DNA [8]. Hydroxyl radicals can be generated in biological systems endogenously and exogenously [9], and the sources include a variety of different processes such as cellular metabolic processes, radiolysis, photolysis, and Fenton chemistry [10-12]. Elucidation of the $\mathrm{OH}$-induced oxidation mechanism of amino acids, peptides, and proteins is of exceptional importance for physiological chemistry (e.g., for understanding the relationship between protein oxidation and aging) [13-16] and also of considerable interest for the Earth's atmosphere [17, 18]. 
Hydroxyl radicals undergo several types of reactions with amino acids, peptides, and proteins. Typical reactions include addition, electron transfer, and hydrogen abstraction $[14,15]$. The $\mathrm{OH}$ radicals can attack both amino acid side chains and the peptide backbone, generating a large number of different radical derivatives of proteins $[19,20]$. With respect to the peptide backbone cleavage, the main reaction pathway is initiated by an $\mathrm{H}$ abstraction at the $\alpha$-carbon position. This is followed by a reaction with $\mathrm{O}_{2}$ to give a peroxyl radical, which ultimately results in fragmentation and cleavage of the backbone of the protein, thereby mainly forming amide and carbonyl fragments [11,21]. Several studies have demonstrated that the $\mathrm{H}$ abstraction from the $\alpha$-carbon position is the dominant pathway for the $\mathrm{OH}$-mediated fragmentation of proteins and occurs at specific sites or amino acid residues as shown by computational and experimental investigations $[9$, $22,23]$. Also, the metal-catalyzed oxidation (MCO) of proteins was found to be an important pathway for protein degradation, as metal ions preferentially bind particular sites of proteins, resulting in selective damage [14, 24-26]. Among the multiple oxidation products, carbonyl compounds, peptide-bound hydroperoxides, and larger protein fragments were predominantly identified [27-30]. For example, Morgan et al. [28] investigated the site selectivity of peptide-bound hydroperoxide and alcohol group formation, as well as fragment species formed through protein oxidation by $\mathrm{OH} / \mathrm{O}_{2}$ using a mass spectrometry (MS) approach.

The high reactivity of proteins with $\mathrm{OH}$ radicals, however, may result in various products due to different reaction mechanisms [31, 32]. In this study, we focus on the identification and quantification of amino acids as oxidation products of proteins and peptides generated by hydroxyl radicals from the Fenton reaction. For this purpose, we introduced two robust analytical methods based on mass spectrometry and liquid chromatography, which have been widely used for the determination of amino acids in various environments (e.g., plasma and plant extracts) [33, 34]. These methods provide analytical evidence for the release of amino acids due to the $\mathrm{OH}$-mediated oxidation of peptides and enable their yields to be quantified.

Bovine serum albumin (BSA) and ovalbumin (OVA) were used as model proteins, and tripeptides with varying amino acid sequences were used to study yields and site selectivity for reactions with $\mathrm{OH}$ radicals. The amino acids consisted of the tripeptides (glycine (Gly), alanine (Ala), serine (Ser), and methionine (Met)) were chosen due to their reactivity towards $\mathrm{OH}$ radicals; i.e., Gly, Ala, and Ser show a low reactivity towards $\mathrm{OH}$, while the rate constant of Met with $\mathrm{OH}$ is about 2 orders of magnitude higher [19]. Oxidation products were analyzed by high-performance liquid chromatography tandem mass spectrometry (HPLC-MS/MS) using a Q-ToF mass spectrometer and pre-column online ortho-phthalaldehyde (OPA) derivatization-based amino acid analysis by HPLC with diode array detection and fluorescence detection to identify and quantify free amino acids. We report the release of free amino acids in the $\mathrm{OH}$ radical-induced oxidation of peptides and proteins. Furthermore, effects of amino acid side chains on the release are discussed with regard to product identification and site selectivity.

\section{Experimental}

\section{Reagents}

BSA (A5611), OVA (grade V, A5503), Gly-Gly-Gly ((Gly), G1377), Met-Ala-Ser (M1004), $\mathrm{NaH}_{2} \mathrm{PO}_{4} \cdot \mathrm{H}_{2} \mathrm{O}$ (71504), OPA (P0657), 9-fluorenylmethoxycarbonyl chloride (FMOC-Cl, 23186), 3-mercatopropionic acid (63768), acetonitrile (ACN, 34998), methanol (MeOH, 494291), amino acid standards (AAS18), asparagine (A0884), glutamine (49419), tryptophan (93659), sodium tetraborate decahydrate $\left(\mathrm{Na}_{2} \mathrm{~B}_{4} \mathrm{O}_{7} \cdot 10 \mathrm{H}_{2} \mathrm{O}\right.$, S9640), $\mathrm{FeSO}_{4} \cdot 7 \mathrm{H}_{2} \mathrm{O}$ (F7002), $\mathrm{H}_{2} \mathrm{O}_{2}$ solution $(30 \%, w / v$, 16911), and $\mathrm{HCl}$ solution (0.1 M, 318965) were purchased from Sigma-Aldrich (Germany). Sodium hydroxide $(\mathrm{NaOH}$, 0583) was from VWR (Germany). Met-Gly-Ala, Gly-AlaMet, and Ala-Met-Gly were obtained from GeneCust (Luxembourg) and were delivered in the desalted form with a purity $>95 \%$. High purity water $(18.2 \mathrm{M} \Omega \mathrm{cm})$ was taken from an ELGA LabWater system (PURELAB Ultra, ELGA, UK) and autoclaved before use if not specified otherwise.

\section{Protein/peptide oxidation reactions}

Reaction mixtures of proteins/peptides (structures shown in Fig. 1) with Fenton oxidants $\left(\mathrm{FeSO}_{4}-\mathrm{H}_{2} \mathrm{O}_{2}\right)$ were stirred (Multistirrer 15, Fischer Scientific, Germany) in closed screw-cap vials at room temperature. Hydroxyl radicals were generated under two oxidation conditions, and the estimated effective $\mathrm{OH}$ concentrations are listed in Table 1 . The $\mathrm{pH}$ of the reaction solutions was adjusted to 3 by adding $1 \mathrm{M} \mathrm{NaOH}$ and measured by a pH meter (Multi 350i; WTW, Weilheim, Germany). Although ethylenediaminetetraacetic acid (EDTA) is a common chelator to stimulate the generation of radicals under physiological pH conditions (pH 6-8) [35], no EDTA was added in this study as glycine was found to be one of the degradation products of EDTA in the presence of $\mathrm{OH}$ [36]. For protein oxidation reactions, the proteins BSA and OVA were pretreated with a size-exclusion column (PD-10, GE Healthcare, Germany) using ultrapure $\mathrm{H}_{2} \mathrm{O}$ to remove low molecular components $(<5 \mathrm{kDa})$. From the purified $25 \mathrm{mg} \mathrm{mL}^{-1}$ protein solutions, $100-\mu \mathrm{L}$ aliquots were added to the Fenton oxidant solutions to a final volume of $2.5 \mathrm{~mL}$. After the respective reaction times, the oxidized samples were immediately eluted on a PD-10 column pre-equilibrated with ultrapure $\mathrm{H}_{2} \mathrm{O}$ to separate the protein and the low molecular 
Fig. 1 Structures of the investigated peptides (a) and proteins (b) in this study. The molecular structures of proteins (BSA, PDB accession number 3V03; OVA, PDB accession number 1OVA) were created using the RCSB PDB protein workshop (4.2.0) software<smiles>CSCCC(N)C(=O)NC(C)C(=O)NC(CO)C(=O)O</smiles><smiles>CSCC(NC(=O)C(C)N)C(=O)NCC(=O)O</smiles>

Ala-Met-Gly<smiles>CSCCC(N)C(=O)NCC(=O)NC(C)C(=O)O</smiles><smiles>CSCCC(NC(=O)C(C)NC(=O)CN)C(=O)O</smiles>

Met-Gly-Ala a Tripeptides: b Proteins:

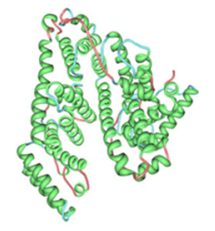

Bovine Serum Albumin (BSA) (67 kD,607 amino acids)

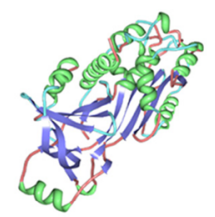

Ovalbumin (OVA)

(45 kD, 386 amino acids) weight fraction $(<5 \mathrm{kDa})$. For peptide oxidation reactions, $100 \mu \mathrm{L}$ of $100 \mathrm{mM}$ solutions of the investigated peptides were added as described before. Control reactions were performed using either $\mathrm{H}_{2} \mathrm{O}_{2}$ or $\mathrm{FeSO}_{4}$ alone at the same concentrations and $\mathrm{pH}$ conditions, adjusted by $0.1 \mathrm{M} \mathrm{HCl}$ and $1 \mathrm{M} \mathrm{NaOH}$, respectively.

In addition, oxidation experiments were performed for peptides with UV-induced $\mathrm{OH}$ generation via the homolysis of $\mathrm{H}_{2} \mathrm{O}_{2}$ in aqueous solution. Briefly, $4 \mathrm{mM}(\mathrm{Gly})_{3}$ were mixed with $50 \mathrm{mM} \mathrm{H}_{2} \mathrm{O}_{2}$ or $200 \mathrm{mM} \mathrm{H}_{2} \mathrm{O}_{2}$ in a $10 \times 10 \times 40 \mathrm{~mm} \mathrm{UV}$ quartz cuvette (Hellma Analytics, Müllheim, Germany) and subsequently irradiated by four UV lamps (wavelength of $254 \mathrm{~nm}$, LightTech, Hungary) for $1 \mathrm{~h}$. The $\mathrm{pH}$ of these samples was also adjusted to 3 by adding $0.1 \mathrm{M} \mathrm{HCl}$. Control samples were either treated the same way as described above, but without UV irradiation, or prepared without $\mathrm{H}_{2} \mathrm{O}_{2}$ and irradiated for $1 \mathrm{~h}$.
All experiments described above were performed in duplicate, and the samples were lyophilized $\left(-40{ }^{\circ} \mathrm{C}, \sim 12 \mathrm{~h}\right) \mathrm{im}-$ mediately after reaction to stop the reaction by removing the hydrogen peroxide. The dry residues were stored at $-20{ }^{\circ} \mathrm{C}$ and redissolved in $100 \mu \mathrm{L} \mathrm{H}_{2} \mathrm{O}$ for analysis.

\section{Amino acid analysis}

The oxidized peptides and low molecular weight fraction of proteins were analyzed with the HPLC-DAD-FLD system (Agilent Technologies 1200 Series) consisting of a binary pump (G1312B), a four-channel microvacuum degasser (G1379B), a column thermostat (G1316B), an autosampler with a thermostat (G1330B), a photo-diode array detector (DAD, G1315C), and a fluorescence detector (FLD, G1321A). ChemStation software (version B.03.01, Agilent) was used to control the system and for the data analysis.
Table 1 Oxidation conditions for the generation of $\mathrm{OH}$ radical in aqueous solutions

\begin{tabular}{lllll}
\hline Condition & Compositions & & $\mathrm{pH}($ adjusted by 1 M NaOH) & {$[\mathrm{OH}]\left(\text { molecule cm }{ }^{-3}\right)^{\mathrm{a}}$} \\
\cline { 2 - 4 } & $\mathrm{FeSO}_{4}(\mathrm{mM})$ & $\mathrm{H}_{2} \mathrm{O}_{2}(\mathrm{mM})$ & & \\
\hline $\mathrm{Ox} 1$ & 5 & 50 & 3 & $1.5 \times 10^{8}$ \\
$\mathrm{Ox} 2$ & 5 & 150 & 3 & $2.1 \times 10^{8}$ \\
\hline
\end{tabular}

${ }^{\mathrm{a}}$ The decay of $(\mathrm{Gly})_{3}$ was monitored and allowed for an estimation of the effective $\mathrm{OH}$ concentration based on a pseudo-first-order kinetic rate function: $\left[(\mathrm{Gly})_{3}\right]=\left[(\mathrm{Gly})_{3}\right]_{0} e^{(-k[\mathrm{OH}] t)}$, where $\left[(\mathrm{Gly})_{3}\right]$ is the recovery of $(\mathrm{Gly})_{3}$, $\left[(\mathrm{Gly})_{3}\right]_{0}$ is the initial recovery (i.e., $\left.100 \%\right), k\left(1.2 \times 10^{-12} \mathrm{~cm}^{3} \mathrm{~s}^{-1}\right)$ is the second-order rate constant for the reaction of $\mathrm{OH}$ with $(\mathrm{Gly})_{3}[16],[\mathrm{OH}]$ is the effective concentration of hydroxyl radical (assuming it remains constant during the reaction), and $t$ is the reaction time. The fitting curves are shown in Fig. S6 in ESM 
Chromatographic conditions were in accordance with the instructions by Agilent Technologies [37]. Briefly, automatic pre-column derivatization with OPA and FMOC was performed at room temperature, according to the injector programs (for details, see Table S1 in Electronic Supplemental Material (ESM)) listed in Henderson et al. [37]. After derivatization, an amount equivalent to $0.5 \mu \mathrm{L}$ of each sample was injected on a Zorbax Eclipse amino acid analysis (AAA) column $(150 \mathrm{~mm} \times 4.6 \mathrm{~mm}$ i.d., $3.5 \mu \mathrm{m}$, Agilent $)$ at a temperature of $40{ }^{\circ} \mathrm{C}$. Mobile phase A was $40 \mathrm{mM} \mathrm{NaH}{ }_{2} \mathrm{PO}_{4}$ (aq), adjusted to $\mathrm{pH} 7.8$ with $10 \mathrm{~N} \mathrm{NaOH}(\mathrm{aq})$, while mobile phase $\mathrm{B}$ was acetonitrile/methanol/water $(45: 45: 10, v / v / v)$. The flow rate was $2 \mathrm{~mL} \mathrm{~min}^{-1}$ with a gradient program that started with $0 \%$ B for 1.9 min followed by a 16.2-min step that raised eluent B to $57 \%$. Then, eluent B was increased to $100 \%$ within $0.5 \mathrm{~min}$ and kept for another $3.7 \mathrm{~min}$. The mobile phase composition was reset to initial conditions within $0.9 \mathrm{~min}$, and the column was equilibrated for $2.8 \mathrm{~min}$ before the next run. Primary amino acids were detected by monitoring the UV absorbance at $338 \mathrm{~nm}$, with a reference at $\lambda=390 \mathrm{~nm}$, bandwidth $=10 \mathrm{~nm}$, slit of $4 \mathrm{~nm}$, and peak width of $>0.1 \mathrm{~min}$, simultaneously detected by FLD with excitation $340 \mathrm{~nm}$, emission $450 \mathrm{~nm}$, and photomultiplier tube (PMT) gain of 10. Secondary amino acids were detected by FLD with excitation $266 \mathrm{~nm}$, emission $305 \mathrm{~nm}$, and PMT gain of 9. A mixture of 20-amino acid standards (see ESM Table S2) was used to obtain calibration curves for quantification as illustrated in Fig. S1 in ESM. The limits of detection (LODs, defined as a signal-to-noise ratio of 3 ) for 20 individual amino acids are in the range of 0.1 to 5 pmol. Linearity is demonstrated for the concentration range of 20 to $500 \mu \mathrm{M}$ for all amino acids by detection using a DAD or FLD.

\section{LC-Q-TOF-MS}

Identification of $\mathrm{OH}$-mediated reaction products of peptides and the low molecular weight fraction of proteins was also carried out using an HPLC-MS/MS system (Agilent). The LC-MS/MS system consists of a quaternary pump (G5611A), an autosampler (G5667A) with a thermostat (G1330B), a column thermostat (G1316C), and an electrospray ionization (ESI) source interfaced to a Q-ToF mass spectrometer (6540 UHD Accurate-Mass Q-ToF, Agilent Technologies). All modules were controlled by MassHunter software (Rev. B. 06.01, Agilent). The LC column was a Zorbax Extend-C18 Rapid Resolution HT $(2.1 \times 50 \mathrm{~mm}, 1.8 \mu \mathrm{m})$ and was operated at a temperature of $30{ }^{\circ} \mathrm{C}$. Eluents used were $3 \%(v / v)$ acetonitrile (Chromasolv, Sigma, Seelze, Germany) in water/formic acid $(0.1 \% v / v$, Chromasolv, Sigma, Seelze, Germany) (eluent A) and 3\% water in acetonitrile (eluent B). The flow rate was $0.2 \mathrm{~mL} \mathrm{~min}{ }^{-1}$ with a gradient program starting with $3 \% \mathrm{~B}$ for 1.5 min followed by an 18-min step that raised eluent B to $60 \%$. Further, eluent $\mathrm{B}$ was increased to $80 \%$ at $20 \mathrm{~min}$ and returned to initial conditions within $0.1 \mathrm{~min}$, followed by column re-equilibration for 9.9 min before the next run. The sample injection volume was $1-5 \mu \mathrm{L}$.

The ESI-Q-TOF instrument was operated in the positive ionization mode (ESI+) with a drying gas temperature of $325^{\circ} \mathrm{C}, 20$ psig nebulizer pressure, $4000 \mathrm{~V}$ capillary voltage, and $75 \mathrm{~V}$ fragmentor voltage. Fragmentation of protonated ions was conducted using the targeted MS/MS mode with a collision energy of $10 \mathrm{~V}$ ( $16 \mathrm{~V}$ for $\mathrm{m} / \mathrm{z}, 76)$. Spectra were recorded over the mass range of $m / z, 50-1000$ for MS mode and $m / z, 20-1000$ for MS/MS mode. Data analysis was performed using the qualitative data analysis software (Rev. B. 06.00, Agilent).

\section{Results and discussion}

\section{Identification of amino acid products in the hydroxyl radical-induced oxidation of peptides and proteins}

Figure 1 shows the tripeptides and proteins investigated in this study. The oxidation products generated by $\mathrm{OH}$ radicals from the Fenton reaction were analyzed by AAA and LC-MS/MS in order to identify and quantify amino compounds and, in particular, amino acid products.

Figure 2 shows the exemplary AAA chromatograms of an amino acid standard, as well as protein and peptide samples oxidized by $\mathrm{OH}$ radicals. The signal corresponding to glycineOPA derivative at a retention time (RT) of 7.8 min was detected in all oxidized samples of glycine-containing peptides and proteins. Moreover, the peak was absent when the oxidized peptide did not contain glycine (i.e., Met-Ala-Ser). LC-MS/ MS analysis of underivatized samples further confirmed the free amino acid glycine to be an oxidation product of proteins and peptides reacting with hydroxyl radicals. Figure 3 shows the MS/MS spectra of a glycine standard $(\mathrm{m} / \mathrm{z}, 76)$ and those of precursor ions with $m / z 76$ found in oxidized BSA, $(\mathrm{Gly})_{3}$, and Ala-Met-Gly samples. In all cases, identical fragmentation patterns were observed and the loss of $16 \mathrm{Da}$ from the precursor ions corresponds to the loss of $\mathrm{NH}_{2}$ [34]. In addition, the signal intensity of extracted ion chromatograms (EICs) for $\mathrm{m} / \mathrm{z}$ 76 in the oxidized samples increased significantly compared to the control samples (see ESM Fig. S2), indicating the formation of an $\mathrm{OH}$-mediated reaction product with $\mathrm{m} / \mathrm{z} 76$ in these samples. Thus, glycine, which does not contain an oxidation sensitive side chain, could be identified as a product of all studied reaction systems of peptides and proteins comprising glycine in their amino acid sequences.

In addition to glycine, three other peaks exhibiting the RT of OPA derivatives of aspartic acid (Asp), asparagine (Asn), and Ala were detected in the AAA of oxidized protein (BSA and OVA) samples, i.e., at $2.1 \mathrm{~min}$ for Asp, $6.4 \mathrm{~min}$ for Asn, 


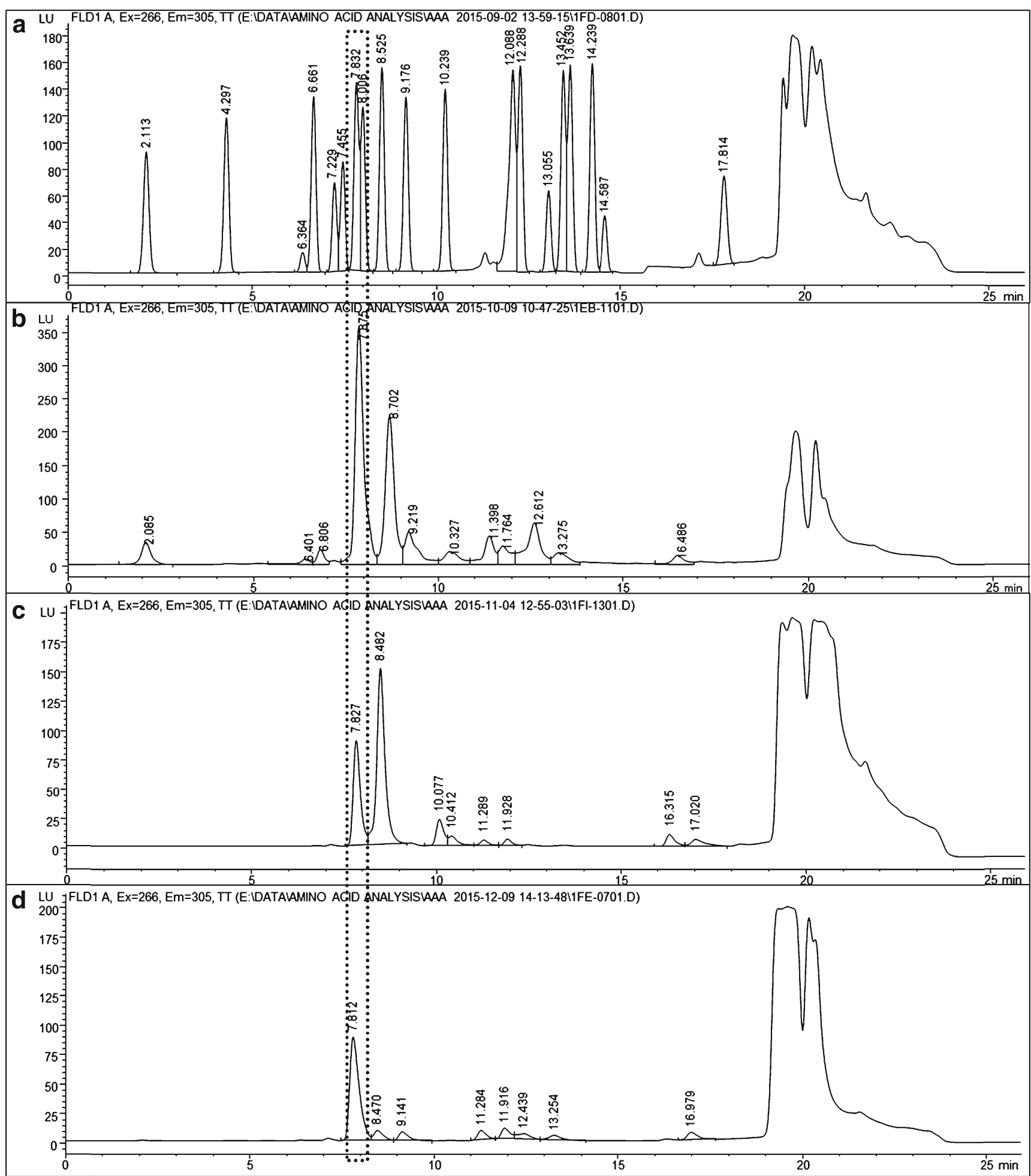

Fig. 2 Amino acid analysis (AAA) with fluorescence detection of OPA-derivatized amino acids: (A) $200 \mu \mathrm{M}$ of a 20 -amino acid standard; (B) $15 \mu \mathrm{M}$ BSA, Ox2, $24 \mathrm{~h}$; (C) $4 \mathrm{mM}$ tri-Gly, Ox1, $0.25 \mathrm{~h}$; and (D) $4 \mathrm{mM}$ Ala-Met-Gly, Ox1, $19 \mathrm{~h}$. The dotted box indicates the signal of glycine in all samples

and 9.2 min for Ala, as illustrated in Fig. 2B. The LC-MS/MS analysis of reference compounds and samples confirmed the identity of the amino acids as shown in Fig. S3 in ESM [34, 38]. It should be noted that the four free amino acids (Asp,
Asn, Gly, and Ala) identified in oxidized protein samples, all exhibit a low rate constant for reactions with $\mathrm{OH}[19,39]$, resulting in a higher stability towards further reactions with $\mathrm{OH}$ radicals and enabling their identification in the analysis. 
Fig. 3 The $\mathrm{MS}^{2}$ spectra of $m / z, 76$ in (A) $1 \mathrm{mM} \mathrm{Gly,} \mathrm{(B)} \mathrm{oxidized}$ BSA sample in Ox2 condition, (C) $(\text { Gly })_{3}$ in $\mathrm{Ox} 1$ condition, and (D) Ala-Met-Gly in Ox1 condition $\left(\mathrm{Ox} 1,5 \mathrm{mM} \mathrm{FeSO}_{4}\right.$ $50 \mathrm{mM} \mathrm{H}_{2} \mathrm{O}_{2} ; \mathrm{Ox} 2,5 \mathrm{mM}$ $\mathrm{FeSO}_{4}-150 \mathrm{mM} \mathrm{H}_{2} \mathrm{O}_{2}$ ). The oxidized samples show an accurate mass of precursor ion $\mathrm{m} / \mathrm{z} .76$ with the glycine standard, and they exhibit the same fragments of $m / z 60$. The extracted ion chromatograms (EICs) of $m / z, 76$ for the above samples are shown in Fig. S2 in ESM

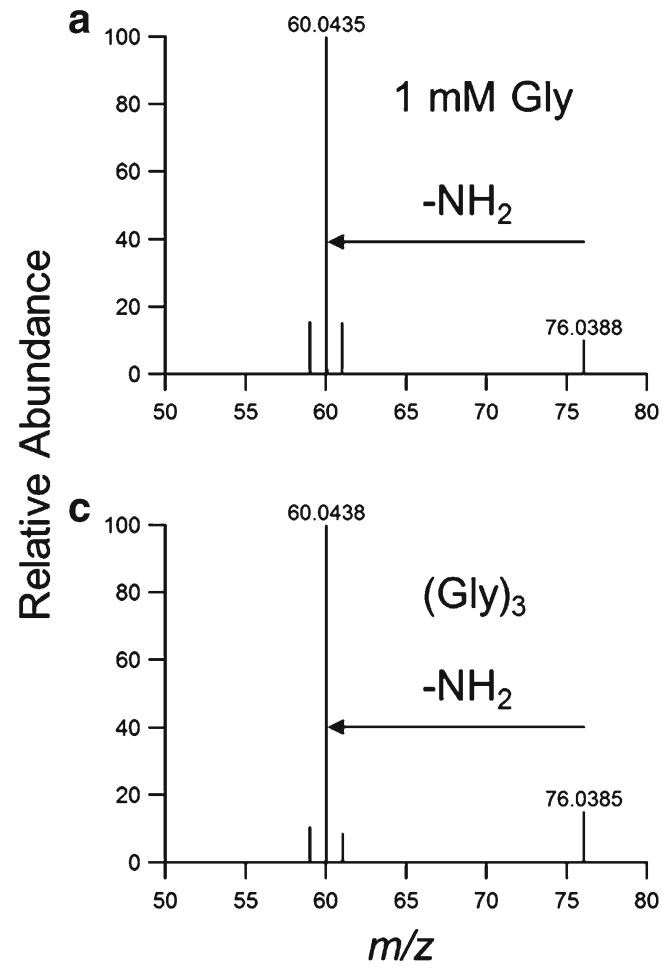

Furthermore, Ala and Asp were unambiguously identified by LC-MS/MS in the oxidized Met-Gly-Ala and Gly-Ala-Met samples. Exemplary $\mathrm{MS}^{2}$ spectra of reference standards and samples are shown in Fig. S4 in ESM. The presence of Asp in the tripeptide samples can be explained by the $\mathrm{OH}$-induced oxidative modification of methionine (Met), as suggested by $\mathrm{Xu}$ and Chance [11] and illustrated in Fig. S5 in ESM. Note that Asp was not identified in the oxidized Ala-Met-Gly sample. This discrepancy may be explained by the formation of other oxidation products of Met, which can be formed when Met is located in the middle of the peptide, as Met is highly reactive towards $\mathrm{OH}$ and the reaction could result in different oxidized species [11]. In the oxidized Met-Ala-Ser sample, the amino acids Asp, Ala, and Ser were identified. Here, Ser could be released directly from the $\mathrm{C}$-terminal position or it could be formed by the oxidation of the methyl side chain of Ala released from the peptide [40]. Therefore, from the combined AAA and LC-MS/MS results, we can confirm that free amino acids are products in the $\mathrm{OH}$-induced oxidation of proteins and peptides.

\section{Quantification and site selectivity of amino acid formation}

Figure 4 shows the molar yields of free amino acids for the $\mathrm{OH}$ oxidation of two model proteins (BSA and OVA) quantified by AAA, whereby yields increased with increasing oxidant concentrations. The yields of Gly were found to be the highest among the quantified amino acids and ranged from $\sim 32$ to $55 \%$ for BSA and from $\sim 10$ to $21 \%$ for OVA.
Notably, the Gly yield of BSA was approximately two to three times higher than that of OVA under the same conditions, despite the higher number of Gly residues in OVA (19) compared to BSA (17). The factors influencing the yields of individual free amino acids in the studied reactions might be multiple, including different tertiary and primary structures and thus different numbers of accessible sites available for the $\mathrm{OH}$ attack, as well as differences in adjacent amino acids in BSA and OVA, influencing OH site selectivity [19].

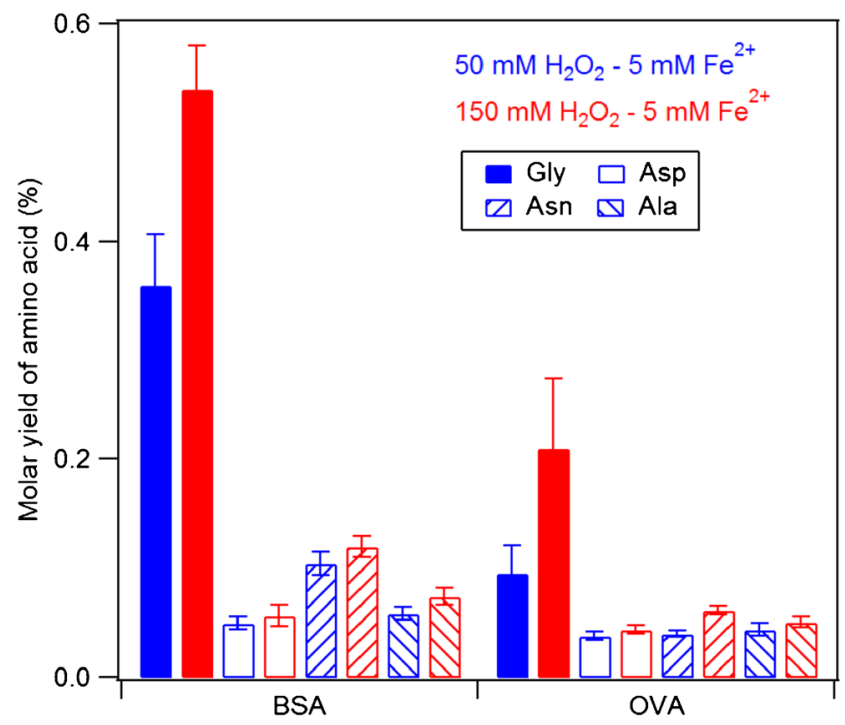

Fig. 4 Molar yields of amino acids obtained in the oxidation of BSA and OVA samples with different concentrations of oxidants (50 and $150 \mathrm{mM}$ $\mathrm{H}_{2} \mathrm{O}_{2}$ with $5 \mathrm{mM} \mathrm{FeSO}_{4}$, respectively) 
Figure 5 shows the temporal evolution of the Gly yield during the oxidation of $(\mathrm{Gly})_{3}$ by $\mathrm{OH}$ radicals. The corresponding recovery of $(\mathrm{Gly})_{3}$ (see ESM Fig. S6) was obtained through AAA analysis using a calibration curve made by a set of $(\text { Gly) })_{3}$ solutions (see ESM Fig. S7). We found that the recovery of $(\mathrm{Gly})_{3}$ has declined to $50 \%$ after $1 \mathrm{~h}$ of reaction (see ESM Fig. S6), while the molar yield of glycine only reached $6 \%$ of (Gly) 3 . Additionally, the molar ratio of free Gly to reacted (Gly) $\left(\Delta(\mathrm{Gly})_{3}=(\mathrm{Gly})_{3, t=0}-(\mathrm{Gly})_{3, t=x}\right)$ was relatively stable over the reaction time with a value of $\sim 12 \%$. These results indicate that other reaction products than Gly are accounting for $\sim 88 \%$ of the reacted peptide. These products may include, e.g., carbonyl species known to be products of the $\alpha$-carbon $\mathrm{H}$ abstraction pathway [28]. To exclude an influence of acidic or basic hydrolysis on the observed formation of glycine [41], control experiments were conducted, in which $(\mathrm{Gly})_{3}$ was incubated under acidic $(\mathrm{pH} 2)$ and basic $(\mathrm{pH} 12)$ conditions for $24 \mathrm{~h}$, respectively. No glycine formation was observed in these experiments. Furthermore, we found that amino acids were also released in the absence of iron ions. This was confirmed through control experiment, in which $\mathrm{OH}$ radicals were generated by the photolysis of $\mathrm{H}_{2} \mathrm{O}_{2}$, and a positive relationship between glycine yield and $\mathrm{H}_{2} \mathrm{O}_{2}$ concentrations was observed (see ESM Fig. S8).

Furthermore, we found the amino acid yields of three small peptides (Ala-Met-Gly, Met-Gly-Ala, and Gly-AlaMet) are dependent on the sequence of Gly, Ala, and Met, as shown in Fig. 6. The highest yields of Gly and Ala were obtained when they were located at the C-terminus, followed by the mid-chain position and the N-terminal site. While the Gly concentration was increasing with reaction time, the Ala concentration already showed a reduction after $2 \mathrm{~h}$ of reaction time when located at the C-terminal site (Met-Gly-Ala), which may be due to further oxidation of free Ala by $\mathrm{OH}$ radicals. Besides, comparing the results in the case of Gly and Ala both located in the same position of the respective tripeptide, the yield of Gly was about $50 \%$ higher than that of Ala when they are located $\mathrm{C}$-terminally. For mid-chain and N-terminal sites, their yields were more comparable. These results suggest that the $\mathrm{OH}$ attack for the release of free amino acids preferably occurs at Gly, particularly for Gly located at the C-terminal site and, to a less extent, at Ala. Previous studies have suggested that $\mathrm{OH}$-mediated fragmentation of proteins likely occur at specific sites rather than giving rise to random fragments [23, 28, 42]. Glycine residues could be favorable sites for $\mathrm{OH}$ attacking the polypeptide backbone due to its low steric hindrance [11]. It should be noted that the highest molar yield of Gly was found to be $\sim 2 \%$ of the corresponding tripeptide (Ala-Met-Gly), confirming free amino acids to

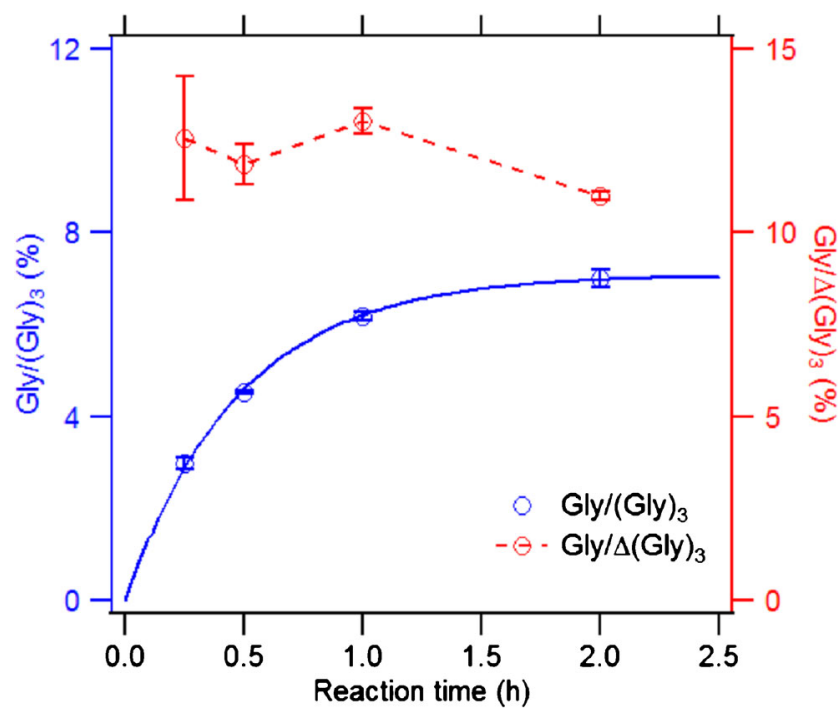

Fig. 5 The temporal evolution of molar yield Gly/(Gly) $)_{3}$ (blue dots) and the product ratio of Gly to $\Delta(\mathrm{Gly})_{3}$ (red dots) in the oxidation of $4 \mathrm{mM}$ $(\text { Gly })_{3}$ with $5 \mathrm{mM} \mathrm{FeSO}_{4}-50 \mathrm{mM} \mathrm{H}_{2} \mathrm{O}_{2}$ condition $(\mathrm{Ox} 1) . \Delta(\mathrm{Gly})_{3}$ was quantified by a calibration curve made by a set of (Gly) 3 solutions (see ESM Fig. S7) monitored at a UV absorbance of $338 \mathrm{~nm}$. The solid line (blue) is fitted with a pseudo-first-order kinetic rate function: $[\mathrm{AA}]=a[\text { TriPep }]_{0}\left(1-e^{-k[\mathrm{OH}] t}\right)$, as discussed in the "Quantification and site selectivity of amino acid formation" section

be low yield products and explaining the lack of reports in the literature.

Aspartic acid, the $\mathrm{OH}$ oxidation product of Met, was found in Met-Gly-Ala and Gly-Ala-Met. In contrast to the observed increasing yield of Gly and Ala for the C-terminal site, the Asp yields were found to be higher for the N-terminal site than for the C-terminal site, i.e., $0.7 \%$ in Met-Gly-Ala and only $0.1 \%$ in Gly-Ala-Met. The site selectivity for the $\mathrm{OH}$ attack at Gly may also explain why the yield of Asp was higher for Met at the $\mathrm{N}$-terminal site than at the C-terminal site, since in MetGly-Ala, the attack on Gly may lead to the formation of Met or its oxidized product as a "byproduct". Additionally, the temporal evolution of release for amino acids in Figs. 5 and 6 can be fitted with a pseudo-first-order rate function: $[\mathrm{AA}]=a[\text { TriPep }]_{0}\left(1-e^{-k[\mathrm{OH}] t}\right)$, where the coefficient $a$ stands for the maximum molar yield for the release of the specific amino acid, $k$ is the second-order rate coefficient, $t$ is the reaction time, and $[\mathrm{AA}]$, $[\text { TriPep }]_{0}$, and $[\mathrm{OH}]$ are the concentrations of amino acids, tripeptide $(4 \mathrm{mM})$, and $\mathrm{OH}$ $\left(1.5 \times 10^{8} \mathrm{~mol} \mathrm{~cm}^{-3}\right.$, assuming $[\mathrm{OH}]$ is constant), respectively. The second-order rate coefficient for the release of amino acids from the four investigated tripeptides is in the order of magnitude of $10^{-12} \mathrm{~cm}^{3} \mathrm{~s}^{-1}$. The maximum molar yield for all the amino acids was from $0.0014 \pm 0.0018$ to $0.0709 \pm 0.0011$, with the highest found for Gly in $(\mathrm{Gly})_{3}(0.0709 \pm 0.0011)$; the detailed coefficients from fittings can be found in Table S3 in ESM. The kinetics and mechanism will be further investigated in follow-up studies. 


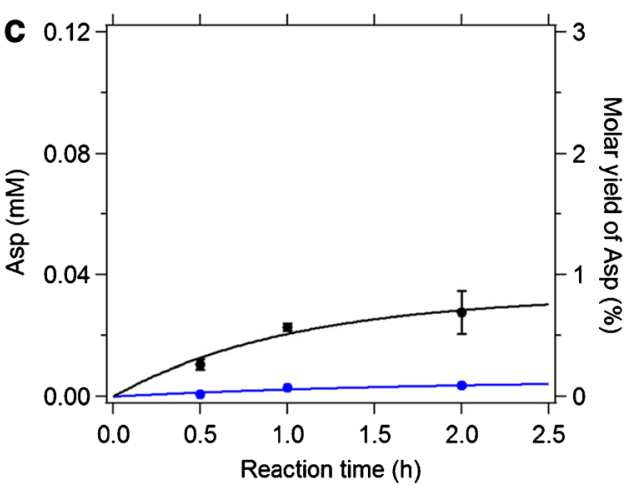

Fig. 6 Temporal evolution of the concentration (left axis) and molar yield (right axis) of glycine (A), alanine (B), and aspartic acid $(\mathbf{C})$ from Gly-Ala-Met, Met-Gly-Ala, and Ala-Met-Gly subjected to the oxidation with $5 \mathrm{mM} \mathrm{FeSO}_{4}-$ $50 \mathrm{mM} \mathrm{H}_{2} \mathrm{O}_{2}$ (Ox1). The solid lines are fitted with a pseudo-firstorder kinetic rate function: $[\mathrm{AA}]=a[\text { TriPep }]_{0}\left[1-e^{-k[\mathrm{OH}] t}\right]$, as discussed in the "Quantification and site selectivity of amino acid formation" section. For the fitting for Ala in Ala-Met-Gly, it is only

fitted for the first two data points
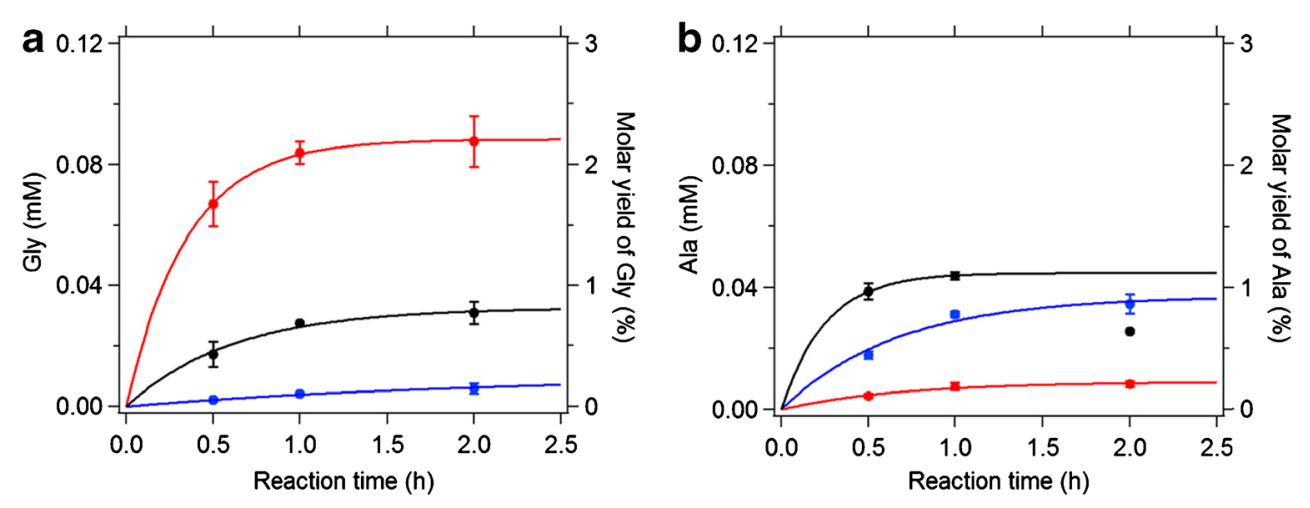

previous studies, Štefanić et al. [43] determined that the amide nitrogen is the preferred site for $\mathrm{OH}$ attack through pulse radiolysis on free glycine and a glycine anion, whereas Doan et al. [9] concluded that $\mathrm{H}$ abstraction from the peptide nitrogen atom is the least preferred site for $\mathrm{OH}$ attack at the peptide backbone by ab initio calculations. The key difference for the contradiction in the above two studies is that the former investigated isolated amino acids while the latter used peptide systems for their calculation methods. Also, the electron transfer between sites resulting in secondary fragmentation or rearrangement [14, 44], should be considered for the formation of nitrogen-centered radicals. Further verification of the generation of nitrogen-centered radicals and the investigation of their role for the release of amino acids via protein/peptide oxidation by hydroxyl radicals could be obtained by techniques such as electron paramagnetic resonance (EPR) spectroscopy in follow-up studies [45, 46].

Acknowledgements Open access funding provided by Max Planck Society. F.L. and S.L. acknowledge the financial support from the China Scholarship Council (CSC), and C.J.K. acknowledges the support by the Max Planck Graduate Center (MPGC) with the Johannes Gutenberg University Mainz and the financial support by the German Research Foundation (DFG, grant no. KA4008/1-2).

\section{Compliance with ethical standards}

Conflict of interest The authors declare that they have no competing interests. 
Ethical approval This article does not contain any research with human participants or animals.

All authors of this manuscript were informed and agreed for submission.

Open Access This article is distributed under the terms of the Creative Commons Attribution 4.0 International License (http:// creativecommons.org/licenses/by/4.0/), which permits unrestricted use, distribution, and reproduction in any medium, provided you give appropriate credit to the original author(s) and the source, provide a link to the Creative Commons license, and indicate if changes were made.

\section{References}

1. Waris G, Ahsan H. Reactive oxygen species: role in the development of cancer and various chronic conditions. J Carcinog. 2006;5:14.

2. Valko M, Jomova K, Rhodes CJ, Kuča K, Musílek K. Redox-and non-redox-metal-induced formation of free radicals and their role in human disease. Arch Toxicol. 2016;90:1-37.

3. Oyinloye BE, Adenowo AF, Kappo AP. Reactive oxygen species, apoptosis, antimicrobial peptides and human inflammatory diseases. Pharmaceuticals. 2015;8:151-75.

4. Pöschl U, Shiraiwa M. Multiphase chemistry at the atmospherebiosphere interface influencing climate and public health in the anthropocene. Chem Rev. 2015;115:4440-75.

5. Wang Y, Chen J, Ling M, López JA, Chung DW, Fu X. Hypochlorous acid generated by neutrophils inactivates ADAMTS13 an oxidative mechanism for regulating ADAMTS13 proteolytic activity during inflammation. J Biol Chem. 2015;290:1422-31.

6. Chen X, Mou Y, Ling J, Wang N, Wang X, Hu J. Cyclic dipeptides produced by fungus Eupenicillium brefeldianum HMP-F96 induced extracellular alkalinization and $\mathrm{H}_{2} \mathrm{O}_{2}$ production in tobacco cell suspensions. World J Microbiol Biotechnol. 2015;31:247-53.

7. Abu-Soud HM, Maitra D, Shaeib F, Khan SN, Byun J, Abdulhamid I, et al. Disruption of heme-peptide covalent cross-linking in mammalian peroxidases by hypochlorous acid. J Inorg Biochem. 2014;140:245-54.

8. Kocha T, Yamaguchi M, Ohtaki H, Fukuda T, Aoyagi T. Hydrogen peroxide-mediated degradation of protein: different oxidation modes of copper-and iron-dependent hydroxyl radicals on the degradation of albumin. BBA-Protein Struct M. 1997;1337:319-26.

9. Doan HQ, Davis AC, Francisco JS. Primary steps in the reaction of $\mathrm{OH}$ radicals with peptide systems: perspective from a study of model amides. J Phys Chem A. 2010;114:5342-57.

10. Apel K, Hirt H. Reactive oxygen species: metabolism, oxidative stress, and signal transduction. Annu Rev Plant Biol. 2004;55:37399.

11. $\mathrm{Xu} \mathrm{G}$, Chance MR. Hydroxyl radical-mediated modification of proteins as probes for structural proteomics. Chem Rev. 2007; 107:3514-43.

12. Watson C, Janik I, Zhuang T, Charvátová O, Woods RJ, Sharp JS. Pulsed electron beam water radiolysis for submicrosecond hydroxyl radical protein footprinting. Anal Chem. 2009;81:2496-505.

13. Stadtman E, Levine R. Free radical-mediated oxidation of free amino acids and amino acid residues in proteins. Amino Acids. 2003;25:207-18.

14. Davies MJ. Protein oxidation and peroxidation. Biochem J. 2016;473:805-25.

15. Štefanić I, Ljubić I, Bonifačić M, Sabljić A, Asmus K-D, Armstrong DA. A surprisingly complex aqueous chemistry of the simplest amino acid. A pulse radiolysis and theoretical study on $\mathrm{H} /$
D kinetic isotope effects in the reaction of glycine anions with hydroxyl radicals. Phys Chem Chem Phys. 2009;11:2256-67.

16. Stadtman ER. Protein oxidation and aging. Science. 1992;257:1220-4.

17. Cape J, Cornell S, Jickells T, Nemitz E. Organic nitrogen in the atmosphere-where does it come from? A review of sources and methods. Atmos Res. 2011;102:30-48.

18. McGregor KG, Anastasio C. Chemistry of fog waters in California's Central Valley: 2. Photochemical transformations of amino acids and alkyl amines. Atmos Environ. 2001;35:1091-104.

19. Sharma VK, Rokita SE. Oxidation of amino acids, peptides, and proteins: kinetics and mechanism. John Wiley \& Sons; 2012.

20. Stadtman ER. Protein oxidation and aging. Free Radic Res. 2006;40:1250-8.

21. Davies MJ. The oxidative environment and protein damage. BBAProteins Proteom. 1703;2005:93-109.

22. Rauk A, Armstrong DA. Influence of $\beta$-sheet structure on the susceptibility of proteins to backbone oxidative damage: preference for $\alpha \mathrm{c}$-centered radical formation at glycine residues of antiparallel $\beta$ sheets. J Am Chem Soc. 2000;122:4185-92.

23. Hawkins C, Davies M. EPR studies on the selectivity of hydroxyl radical attack on amino acids and peptides. J Chem Soc Perk Trans. 1998;2:2617-22.

24. Dufield DR, Wilson GS, Glass RS, Schöneich C. Selective sitespecific Fenton oxidation of methionine in model peptides: evidence for a metal-bound oxidant. J Pharm Sci. 2004;93:1122-30.

25. Uehara H, Luo S, Aryal B, Levine RL, Rao VA. Distinct oxidative cleavage and modification of bovine [Cu-Zn]-SOD by an ascorbic $\mathrm{acid} / \mathrm{Cu}$ (II) system: identification of novel copper binding site on SOD molecule. Free Radic Bio Med. 2016;94:161-73.

26. Zhou X, Mester C, Stemmer PM, Reid GE. Oxidation-induced conformational changes in calcineurin determined by covalent labeling and tandem mass spectrometry. Biochemistry-US. 2014;53(43):6754-65.

27. Morgan PE, Pattison DI, Hawkins CL, Davies MJ. Separation, detection, and quantification of hydroperoxides formed at side-chain and backbone sites on amino acids, peptides, and proteins. Free Radic Biol Med. 2008;45:1279-89.

28. Morgan PE, Pattison DI, Davies MJ. Quantification of hydroxyl radical-derived oxidation products in peptides containing glycine, alanine, valine, and proline. Free Radic Biol Med. 2012;52:328-39.

29. Guedes S, Vitorino R, Domingues R, Amado F, Domingues P. Oxidation of bovine serum albumin: identification of oxidation products and structural modifications. Rapid Commun Mass Spectrom. 2009;23:2307-15.

30. Marx G, Chevion M. Site-specific modification of albumin by free radicals. Reaction with copper(II) and ascorbate. Biochem J. 1986;236:397-400.

31. Catalano CE, Choe YS, de Montellano PO. Reactions of the protein radical in peroxide-treated myoglobin. Formation of a heme-protein cross-link. J Biol Chem. 1989;264:10534-41.

32. Lee SH, Kyung H, Yokota R, Goto T, Oe T. Hydroxyl radicalmediated novel modification of peptides: N-terminal cyclization through the formation of $\alpha$-ketoamide. Chem Res Toxicol. 2014;28:59-70.

33. Schwarz EL, Roberts WL, Pasquali M. Analysis of plasma amino acids by HPLC with photodiode array and fluorescence detection. Clin Chim Acta. 2005;354:83-90.

34. Thiele B, Füllner K, Stein N, Oldiges M, Kuhn AJ, Hofmann D. Analysis of amino acids without derivatization in barley extracts by LC-MS-MS. Anal Bioanal Chem. 2008;391:2663-72.

35. Baron CP, Refsgaard HH, Skibsted LH, Andersen ML. Oxidation of bovine serum albumin initiated by the Fenton reaction-effect of EDTA, tert-butylhydroperoxide and tetrahydrofuran. Free Radic Res. 2006;40:409-17. 
36. Oviedo C, Contreras D, Freer J, Rodriguez J. Fe(III)-EDTA complex abatement using a catechol driven Fenton reaction combined with a biological treatment. Environ Technol. 2004;25:801-7.

37. Henderson J, Ricker R, Bidlingmeyer B, Woodward C. Rapid, accurate, sensitive, and reproducible HPLC analysis of amino acids. Agilent Technologies. Technical Note 5980-1193E, J. R. Soc. Interface 9. 2000.

38. Gómez-Ariza J, Villegas-Portero M, Bernal-Daza V. Characterization and analysis of amino acids in orange juice by HPLC-MS/MS for authenticity assessment. Anal Chim Acta. 2005;540:221-30.

39. Buxton GV, Greenstock CL, Helman WP, Ross AB. Critical review of rate constants for reactions of hydrated electrons, hydrogen atoms and hydroxyl radicals $\left(\cdot \mathrm{OH} / \cdot \mathrm{O}^{-}\right.$in aqueous solution). $\mathrm{J}$ Phys Chem Ref Data. 1988;17:513-886.

40. Bachi A, Dalle-Donne I, Scaloni A. Redox proteomics: chemical principles, methodological approaches and biological/biomedical promises. Chem Rev. 2012;113:596-698.

41. Le Maux S, Nongonierma AB, Barre C, FitzGerald RJ. Enzymatic generation of whey protein hydrolysates under $\mathrm{pH}$-controlled and non $\mathrm{pH}$-controlled conditions: impact on physicochemical and bioactive properties. Food Chem. 2016;199:246-51.

42. Uchida K, Kato Y, Kawakishi S. A novel mechanism for oxidative cleavage of prolyl peptides induced by the hydroxyl radical. Biochem Biophys Res Commun. 1990;169:265-71.

43. Štefanić I, Bonifačić M, Asmus K-D, Armstrong DA. Absolute rate constants and yields of transients from hydroxyl radical and $\mathrm{H}$ atom attack on glycine and methyl-substituted glycine anions. J Phys Chem A. 2001;105:8681-90

44. Hawkins CL, Davies MJ. Generation and propagation of radical reactions on proteins. BBA-Bioenergetics. 2001;1504: 196-219.

45. Tong H, Arangio AM, Lakey PS, Berkemeier T, Liu F, Kampf CJ, et al. Hydroxyl radicals from secondary organic aerosol decomposition in water. Atmos Chem Phys. 2016;16:1761-71.

46. Arangio AM, Tong H, Socorro J, Pöschl U, Shiraiwa M. Quantification of environmentally persistent free radicals and reactive oxygen species in atmospheric aerosol particles. Atmos Chem Phys. 2016;16:13105-19. 